40th "Jaszowiec" International School and Conference on the Physics of Semiconductors, Krynica-Zdrój 2011

\title{
Raman Spectroscopy of $\mathrm{LiFePO}_{4}$ and $\mathrm{Li}_{3} \mathrm{~V}_{2}\left(\mathrm{PO}_{4}\right)_{3}$ Prepared as Cathode Materials
}

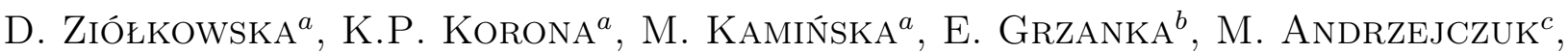 \\ S.-H. WU ${ }^{d}$ AND M.-S. CHEN ${ }^{d}$ \\ ${ }^{a}$ Faculty of Physics, University of Warsaw, Hoża 69, 00-681 Warsaw, Poland \\ ${ }^{b}$ Institute of High Pressure Physics, Polish Academy of Sciences, Sokołowska 29/37, 01-142 Warsaw, Poland \\ ${ }^{c}$ Faculty of Materials Science and Eng., Warsaw Univ. of Technology, Wołoska 141, 02-507 Warsaw, Poland \\ ${ }^{d}$ Department of Materials Engineering, Tatung University, Taipei, Taiwan
}

\begin{abstract}
Structure of samples of lithium iron vanadium phosphates of different compositions were investigated by X-rays, electron microscopy and Raman spectroscopy. The investigated salts were mainly of olivine-like and NASICON-like structures. The X-ray diffraction and the Raman scattering show different crystalline structures, which is probably caused by difference between cores of the crystallites (probed by X-rays) and their shells (probed by the Raman scattering). Most of the Raman spectra were identified with previously published data, however in the samples with high vanadium concentration we have observed new, not reported earlier modes at $835 \mathrm{~cm}^{-1}$ and $877 \mathrm{~cm}^{-1}$, that we identified as oscillations related to $\mathrm{V}_{2} \mathrm{O}_{7}^{4-}$ or $\mathrm{VO}_{4}^{3-}$ anions.
\end{abstract}

PACS: 78.30.Hv, 82.80.Gk, 82.47.Aa

\section{Introduction}

Lithium salts show very interesting phenomenon of ionic conductance when electric charge is carried by $\mathrm{Li}^{+}$ ions moving in the crystal lattice. This effect is used for energy storage applications such as laptops, electric cars and photovoltaic power stations. Nowadays a new class of materials are being developed as active cathode materials: compounds of phospho-olivine and phospho-NASICON structures [1]. In this paper we present the Raman investigations of lithium salts: $\mathrm{LiFePO}_{4}$ and $\mathrm{Li}_{3} \mathrm{~V}_{2}\left(\mathrm{PO}_{4}\right)_{3}$ obtained by solution method [2]. These materials have low cost, good thermal stability, high theoretical capacities: $170 \mathrm{mAh} / \mathrm{g}$ and $197 \mathrm{mAh} / \mathrm{g}$, and high open circuit voltages $3.5 \mathrm{~V}$ and $4.1 \mathrm{~V}$, which makes them good candidates to replace presently used cobalt oxide electrodes [1-3].

\section{Experimental}

The analyzed samples were $\mathrm{LiFePO}_{4}$ and $\mathrm{Li}_{3} \mathrm{~V}_{2}\left(\mathrm{PO}_{4}\right)_{3}$ and their solid solutions. The $\mathrm{LiFePO}_{4}$-based samples were $\mathrm{LiFe}_{1-x} \mathrm{~V}_{x} \mathrm{PO}_{4}$ with vanadium content $x_{\mathrm{V}}$ from 0.01 up to 0.2 . The $\mathrm{Li}_{3} \mathrm{~V}_{2(1-x)} \mathrm{Fe}_{3 x}\left(\mathrm{PO}_{4}\right)_{3}$ samples had iron content $x_{\mathrm{Fe}}=0.01,0.03,0.05,0.07$, and 0.09. All materials were obtained by solution method [2]. The composition was controlled by the inductively coupled plasma optical emission spectrometry (ICP-OES).

X-ray diffraction (XRD) characterization was conducted in Siemens D5000 or X'Pert Pro Panalytical with $\mathrm{Cu} K_{\alpha}$ source in the range $2 \Theta=10-80^{\circ}$ with $0.03^{\circ}$ step. Scanning transmittance electron microscopy (STEM) gave an information about size and morphology of the crystals.
Micro-Raman measurements were made using a Nd:YAG laser with wavelength $532 \mathrm{~nm}$. The spectral resolution was $3 \mathrm{~cm}^{-1}$. Since the laser penetrates much less than one $\mu \mathrm{m}$ into the material, the near-surface region of microcrystals was analyzed.

\section{Results and discussion}

The XRD results (Fig. 1) indicated that undoped $\mathrm{LiFePO}_{4}$ was in single phase olivine structure and $\mathrm{Li}_{3} \mathrm{~V}_{2}\left(\mathrm{PO}_{4}\right)_{3}$ was in monoclinic NASICON-like structure [4]. The analysis of the XRD results showed that lattice parameter of $\mathrm{LiFe}_{1-x} \mathrm{~V}_{x} \mathrm{PO}_{4}$ decreased with increasing content of vanadium: $\Delta a / a=-0.018(6) x_{\mathrm{V}}$, $\Delta b / b=-0.03(1) x_{\mathrm{V}}, \Delta c / c=-0.008(6) x_{\mathrm{V}}$. This suggested that addition of vanadium led to a mixed-cation phospho-olivine crystal containing only so small amounts of other phases, that they features could not be easily distinguished in the XRD.

The average crystallite size calculated using Scherrer's formula was $50-55 \mathrm{~nm}$. On the other hand, the STEM images showed that material consisted of shapeless microcrystals that had sizes between 0.1 and $5 \mu \mathrm{m}$. Comparing these two results we conclude that the sample consisted of small, $50 \mathrm{~nm}$ crystallites agglomerated in bigger grains.

Such structure gives big surface to volume ratio, which is beneficial for the Li-ion cathode material [2]. STEM images showed that the microcrystals were coated by rather amorphous material and the cores of the crystals were highly crystalline (Fig. 2).

Crystal quality of the samples was good enough to observe a lot of sharp phonon lines in the Raman spectroscopy. The olivine vibrations are classified as internal (related to the modes of $\mathrm{PO}_{4}$ tetrahedra) and external ones. The internal modes are assigned as $\nu_{1}, \nu_{2}, \nu_{3}$ 


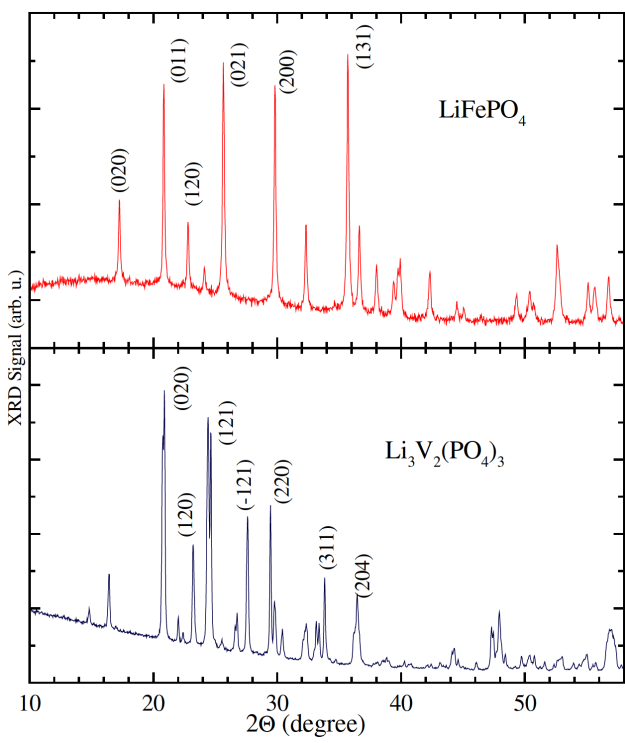

Fig. 1. XRD patterns of pure (upper) $\mathrm{LiFePO}_{4}$ and (lower) $\mathrm{Li}_{3} \mathrm{~V}_{2}\left(\mathrm{PO}_{4}\right)_{3}$.

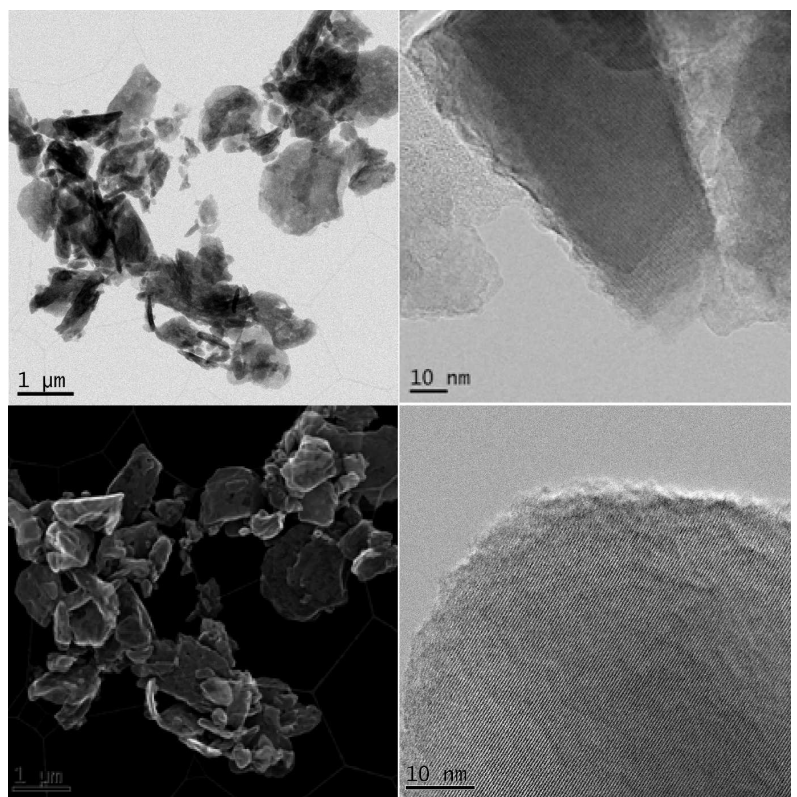

Fig. 2. Transmission electron microscope images of the samples: left - microcrystals, right - atomic structure, upper $-\mathrm{LiFe}_{0.9} \mathrm{~V}_{0.1} \mathrm{PO}_{4}$, lower $-\mathrm{Li}_{3} \mathrm{~V}_{2}\left(\mathrm{PO}_{4}\right)_{3}$.

and $\nu_{4}$ according to Herzberg's notation for the tetrahedron modes [5].

Figure 3 shows spectra of the $\mathrm{LiFe}_{1-x} \mathrm{~V}_{x} \mathrm{PO}_{4}$ samples with different contents of vanadium, $x_{\mathrm{V}}$. Most of the peaks are related to $\mathrm{LiFePO}_{4}$ in olivine structure $[6,7]$. The highest peaks at $990 \mathrm{~cm}^{-1}$ and $1040 \mathrm{~cm}^{-1}$ are most probably $\nu_{3}$ modes, the $444 \mathrm{~cm}^{-1}$ peak is $\nu_{2}$ mode. The fully symmetric $A_{\mathrm{g}} \nu_{1}$ mode was missing in the $\mathrm{LiFePO}_{4}$ Raman spectra. The Raman peaks were relatively broad, their widths were about $50 \mathrm{~cm}^{-1}$. Both these observa- tions suggest some distortion of the structure observed by the Raman spectroscopy. The laser light used for the Raman spectroscopy penetrates much less than $1 \mu \mathrm{m}$ into the material, so it probes mainly the shell of the microcrystals. Comparing the Raman and the XRD results one could conclude that the crystalline quality of the core was better than the shell quality.

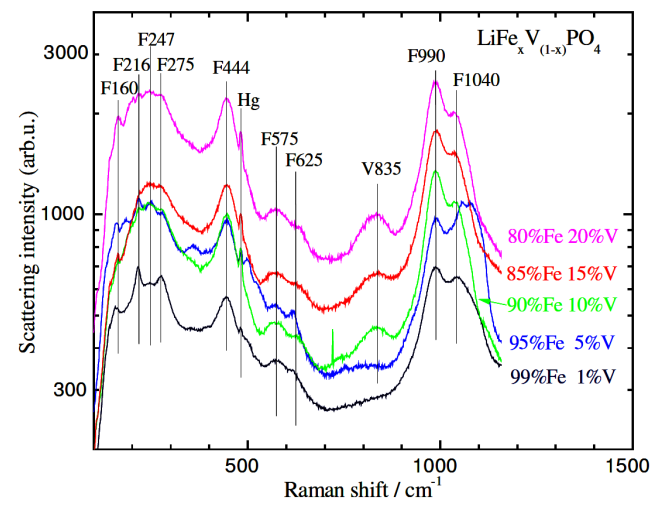

Fig. 3. Raman spectra of $\mathrm{LiFe}_{1-x} \mathrm{~V}_{x} \mathrm{PO}_{4}$ with different $x_{\mathrm{V}}$. Peaks F160-F1040 are related to pure $\mathrm{LiFePO}_{4}$. V835 peak is related to vanadium.

The position of the Raman peaks does not change with addition of V. Only one new peak at $835 \mathrm{~cm}^{-1}$ was observed in the samples with vanadium. Its intensity was rising with increasing $\mathrm{V}$ concentration. It suggested that instead of mixed-cation compound where $\mathrm{V}$ replaces Fe, a new phase containing vanadium was created. These observations contradicted the XRD results. The discrepancy was due to the difference between shell and core part of the crystallites.

The Raman spectra of the $\mathrm{Li}_{3} \mathrm{~V}_{2(1-x)} \mathrm{Fe}_{3 x}\left(\mathrm{PO}_{4}\right)_{3}$ samples with different contents of iron (see Fig. 4) consisted of a lot of sharp peaks. Most of these peaks were present in the sample that had no iron. In Fig. 4 they were labelled from V144 to V1022. Only one peak at $947 \mathrm{~cm}^{-1}$ was correlated with iron content. It has exactly the position of expected $A_{\mathrm{g}} \nu_{1}$ line of $\mathrm{LiFePO}_{4}$ [7].

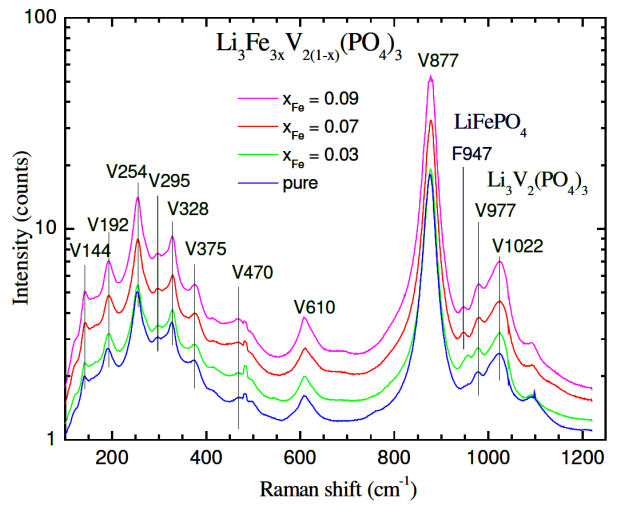

Fig. 4. Raman spectra of $\mathrm{Li}_{3} \mathrm{~V}_{2(1-x)} \mathrm{Fe}_{3 x}\left(\mathrm{PO}_{4}\right)_{3}$ with different contents of iron. 
In the case of the high-vanadium samples, the Raman peaks were sharper than for the samples with a high iron content. Their widths were about $25 \mathrm{~cm}^{-1}$.

The peaks at $977 \mathrm{~cm}^{-1}$ and $1022 \mathrm{~cm}^{-1}$ can be identified as related to $\mathrm{Li}_{3} \mathrm{~V}_{2}\left(\mathrm{PO}_{4}\right)_{3}$ at NASICON-type structure $[3,4,8]$. However, the majority of peaks observed in these samples were not reported previously neither for iron nor for vanadium compounds. The most intense, characteristic peak, present at $877 \mathrm{~cm}^{-1}$, neither was reported.

In order to establish origin of the new peaks, one should estimate frequency $\nu$ of oscillator having effective mass $\mu$ and effective force constant $\kappa$ that can be calculated from classical equation

$$
\nu=\frac{1}{\lambda}=\frac{1}{2 \pi} \frac{1}{c} \sqrt{\frac{\kappa}{\mu}} .
$$

For example, frequency of oxygen oscillation in $\mathrm{P}-\mathrm{O}$ bond is about $1000 \mathrm{~cm}^{-1}$, which is observed in many phosphates. The $\mathrm{V}-\mathrm{O}$ bond is weaker than the $\mathrm{P}-\mathrm{O}$ bond, its strength is $\kappa=6.64 \mathrm{~N} / \mathrm{cm}$ [9], which gives oxygen oscillation frequency of about $820 \mathrm{~cm}^{-1}$. So, most probably the $877 \mathrm{~cm}^{-1}$ peak represents oscillations of oxygen bound to vanadium. In fact, $\mathrm{PO}_{4}^{3-}$ and $\mathrm{VO}_{4}^{3-}$ anions give similar four Raman-active internal modes. The strongest lines correspond to $\nu_{1}\left(A_{1}\right)$ symmetric stretching vibration $[5,10,11]$. Comparing with orthophosphate, orthovanadate lines are shifted to the lower frequencies due to longer $\mathrm{V}-\mathrm{O}$ bond length of about $1.7 \AA[12](\mathrm{P}-\mathrm{O}$ bond length is ca. $1.55 \AA$ [13]) and resulting lower force constant $\kappa$. It was observed that the strongest peaks of $\mathrm{LiCdVO}_{4}$ Raman spectra were at $845 \mathrm{~cm}^{-1}$ and $875 \mathrm{~cm}^{-1}$ [11]. The $\nu_{1}$ mode of $\mathrm{YVO}_{4}$ was reported at $870 \mathrm{~cm}^{-1}[14]$. However, similar frequency $874 \mathrm{~cm}^{-1}$ was reported also for $\mathrm{V}_{2} \mathrm{O}_{7}^{4-}$ anion $\left(\mathrm{VO}_{3}\right.$ terminal group) [10]. So the $877 \mathrm{~cm}^{-1}$ line could be identified as oscillations related to $\mathrm{VO}_{4}^{3-}$ or $\mathrm{V}_{2} \mathrm{O}_{7}^{4-}$ anions.

The Raman investigations of $\mathrm{LiFePO}_{4}$ and high-vanadium phosphate mixtures with ratio 1:1 showed that the vanadium-related peaks were much stronger than the peaks related to the $\mathrm{LiFePO}_{4}$. It was probably due to strong polarization of the $\mathrm{V}-\mathrm{O}$ bonds. This observation explains why the $877 \mathrm{~cm}^{-1}$ peak was more than 2 orders of magnitude stronger than $\nu_{1}\left(\mathrm{LiFePO}_{4}\right)$ peak even in samples with $9 \%$ of iron.

\section{Conclusions}

In the series of samples of lithium salts we have observed phonon modes related to many crystal structures, mainly olivine-like and NASICON-like.

Most of the spectra were identified with previously published data, however in the samples with high vana- dium concentration we have observed new, not reported earlier modes (with the strongest at $877 \mathrm{~cm}^{-1}$ ), that we identified as oscillations related to $\mathrm{VO}_{4}^{3-}$ or $\mathrm{V}_{2} \mathrm{O}_{7}^{4-}$ anions.

X-ray diffraction and the Raman scattering show differences in crystalline structures. The XRD data present high quality, one-phase crystals that change their lattice parameter during doping. The Raman data show new phases, not observed in the XRD. This can be explained by difference between cores of the crystallites (probed by X-rays) and shells (more polycrystalline) probed by the Raman scattering.

\section{Acknowledgments}

The work of D.Z. was supported by the Foundation for Polish Science International Ph.D. Projects Programme co-financed by the EU European Regional Development Fund.

\section{References}

[1] J.W. Fergus, J. Power Sources 195, 939 (2010).

[2] Mu-Rong Yang, Wei-hsin Ke, She-huang Wu, J. Power Sources 165, 646 (2007).

[3] M. Bini, S. Ferrari, D. Capsoni, V. Massarotti, Electrochim. Acta 56, 2648 (2011).

[4] C.M. Burba, R. Frech, Solid State Ionics 177, 3445 (2007).

[5] G. Herzberg, Infrared and Raman Spectra of Polyatomic Molecules, D. Van Nostrand Company, New York 1945

[6] C.V. Ramana, A. Mauger, F. Gendron, C.M. Julien, K. Zaghib, J. Power Sources 187, 555 (2009).

[7] W. Paraguassu, P.T.C. Freire, V. Lemos, S.M. Lala, L.A. Montoro, J.M. Rosolen, J. Raman Spectrosc. 36, 213 (2005).

[8] T. Jiang, W. Pan, J. Wang, X. Bie, F. Du, Y. Wei, C. Wang, G. Chen, Electrochim. Acta 55, 3864 (2010).

[9] P. Clauws, J. Broeckx, J. Vennik, Phys. Status Solidi B 131, 459 (1985).

[10] Yu.K. Voron'ko, A.A. Sobol, V.E. Shukshin, Inorg. Mater. 41, 1097 (2005).

[11] M.Th. Paques-Ledent, P. Tarte, Spectrochim. Acta 30A, 675 (1974).

[12] F.D. Hardcastlet, I.E. Wachs, J. Phys. Chem. 95, 5031 (1991).

[13] L. Popović, B. Manoun, D. de Waal, M.K. Nieuwoudt, J.D. Comins, J. Raman Spectrosc. 34, 77 (2003).

[14] S.A. Miller, H.H. Caspers, H.E. Rast, Phys. Rev. 168, 964 (1968). 